\title{
Comparative Performance of FE-FSM, PM-FSM and HE-FSM with Segmental Rotor
}

\author{
Hassan Ali Soomro ${ }^{a}$, Erwan Sulaiman ${ }^{b}$ and Faisal Khan ${ }^{c}$ \\ Department of Electrical power Engineering, Universiti Tun Hussein Onn Malaysia, \\ Locked bag 101 Batu Pahat, Johor, 86400, Malaysia. \\ aengg.hassansoomro@gmail.com, berwan@uthm.edu.my, ${ }^{c}$ faisalkhan@ciit.net.pk
}

\begin{abstract}
Keywords: Hybrid excitation flux switching motor; Segmental rotor; Field Excitation coil; Permanent magnet; Torque; Power.
\end{abstract}

\begin{abstract}
Flux switching machines (FSMs), new type of electric machines with unique operating principles have been introduced and published recently. FSMs contain armature and excitation sources on the stator with robust rotor structure. According to rotor structure FSMs can be classified into two types namely salient pole rotor and segmental pole rotor. Various topologies have been studied and published using both rotor structures, however salient pole rotor has a demerit of less torque generation due to longer flux path resulting flux leakage surrounding the rotor. In this paper a new structure of hybrid excitation FSM (HEFSM) with segmental rotor is proposed and a comparative analysis with the invented field excitation FSM (FEFSM) and permanent magnet FSM (PMFSM) is presented. Initially, coil arrangement tests are examined to confirm the operating principle of HEFSM with segmental rotor. Moreover, the cogging torque, induced voltage, magnetic flux, torque at various armature current densities and power characteristics are observed based on 2D- finite element analysis (FEA).
\end{abstract}

\section{Introduction}

Flux switching machines (FSMs) that consist of all flux sources in the stator have been developed in recent years due to their definite advantage of single piece robust rotor structure suitable for high speed applications. They can be categorized into three groups that are PMFSM, FEFSM, and HEFSM. Both PMFSM and FEFSM has only permanent magnet (PM) and field excitation coil (FEC), respectively as their main flux sources, while HEFSM combines both PM and FECs [1-2]

Initially, a PMFSM that is permanent magnet single-phase angle actuator or well known as laws relay has been developed [3]. It was further improved to single phase generator with 4 stator slots and 4 or 6 rotor poles. During last years many FSMs designs have been manufactured for different applications, ranging from low cost domestic appliances, automotive and aerospace, etc [4]. In addition, to manufacture the FEFSM, the PM is replaced by DC FE coil on the stator of conventional PMFSMs. In other words, FEFSM with salient rotor structure is a novel topology, merging the principles of the inductor generator and the switch reluctance machines SRMs [5-6].

In more recent work, the use of segmental rotor structure has been adopted for SRMs and single phase FSM which provides more considerable gains over other topologies [7-8]. The basic function of segments in the design is to provide the defined magnetic path for communication of the field flux to the adjacent stator armature coils with the rotation of rotor, to produce bipolar flux linkage in the stator. Using segmental rotor design, arrangement of each coil is around single tooth that provides clear advantage of short end winding. Fig. 1(a), and 1(b), illustrates the basic designs of FEFSM and PMFSM with segmental rotor respectively. By means of this arrangement several advantages are achieved such as less conductor material, low cost and hence improve the performance efficiency of the motor [9].

In this paper a new structure of HEFSM with segmental rotor is presented as shown in Fig. 1(c) obviously the rotor structure is similar with the designs FEFSM and PMFSM in Fig. 1(a) and 1(b) while the additional 6 PMs are placed between FECs of FEFSM to develop a hybrid excitation structure. Then performance of the proposed HEFSM with segmental rotor is compared with 
FEFSM and PMFSM employing segmental rotor under no-load and load characteristics on the basis of 2D- finite element analysis (FEA).

\section{Design restrictions, specifications, and Design Methodology}

The design restrictions, specification and the parameters of the proposed HEFSM with segmental rotor are used similar with FEFSM and PMFSM with segmental rotor structure as listed in Table 1. The maximum limit of current density of armature coil and FEC is set up to $30 \mathrm{Arms} / \mathrm{mm}^{2}$ and $30 \mathrm{~A} / \mathrm{mm}^{2}$ respectively. When employing segmental rotor structure, the use of 12 stator slots is the minimum balanced requirement of three phase configuration, while using 8 rotor segments is influenced by best performance requirements [10]. Using FEA simulation, designs of HEFSM, PMFSM and FEFSM are examined via JMAG-designer ver. 13.0 released by Japan Research Institute (JRI), some discussions on the attributes of each design based on the flux linkages, emf production, flux distribution and cogging torque are addressed.

Table 1 Design specification of 12Slots-8Poles HE-FSM, FE-FSM and PM-FSM with segmental rotor

\begin{tabular}{|c|c|}
\hline Items & HEFSM, FEFSM and PMFSM \\
\hline Number of slots & 12 \\
\hline Number of rotor segments & 8 \\
\hline Stator outer radius [mm] & 75 \\
\hline Stator back inner width [mm] & 11 \\
\hline Stator tooth width $[\mathrm{mm}]$ & 12.5 \\
\hline Armature coil slot area $\left[\mathrm{mm}^{2}\right]$ & 250 \\
\hline FEC slot area $\left[\mathrm{mm}^{2}\right]$ & 250 \\
\hline Rotor outer radius [mm] & 45 \\
\hline Rotor inner radius [mm] & 30 \\
\hline Air gap length [mm] & 0.3 \\
\hline Span of the Segment [degrees] & $40^{0}$ \\
\hline
\end{tabular}

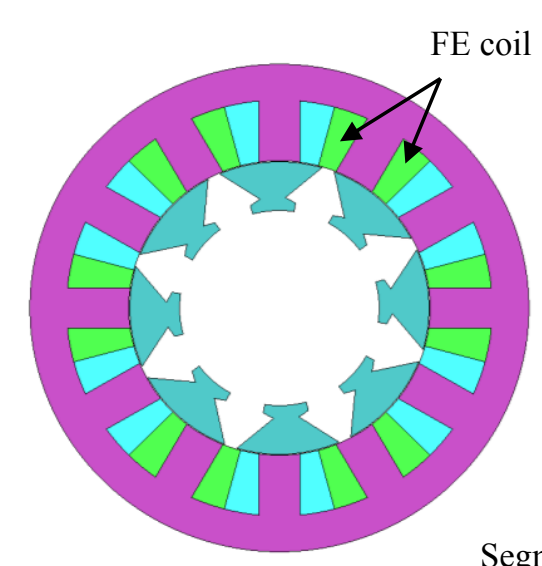

(a)

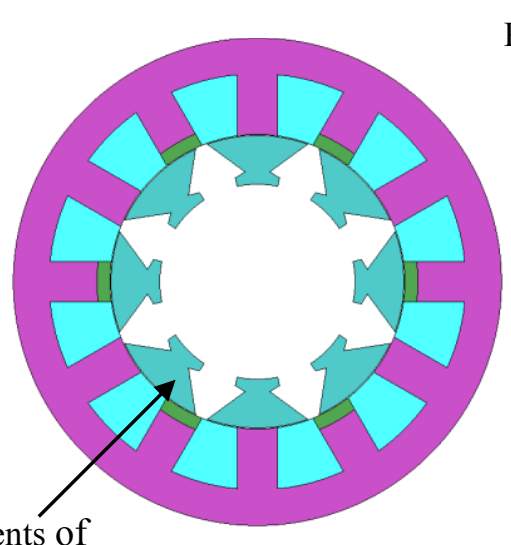

the rotor

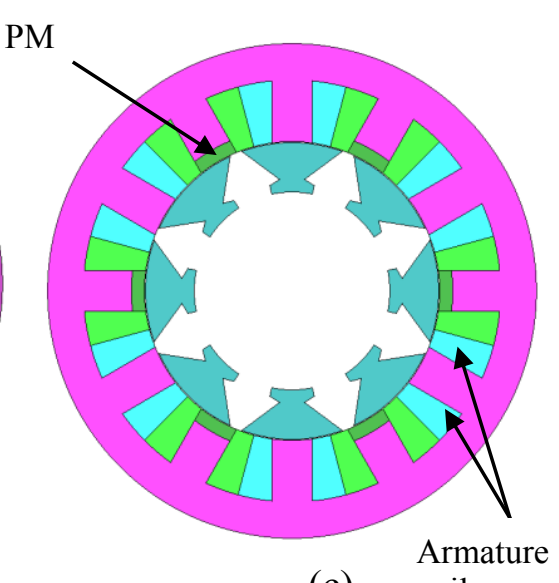

(c)

coil

Fig. 1, (a) FEFSM (b) PMFSM (c) Proposed HEFSM with segmental rotor

\section{Performance comparison of HEFSM, FEFSM and PMFSM}

Induced voltage at no load condition. The induced voltage produced from PM and FEC at maximum Je of $30 \mathrm{~A} / \mathrm{mm}^{2}$ under speed of 500rev/min for HEFSM, PMFSM and FEFSM with segmental rotor at open circuit condition is illustrated in Fig. 2. From the figure, it is clear that HEFSM has the highest induced voltage of approximately $40.16 \mathrm{~V}$, while for FEFSM and PMFSM induced voltage amplitudes reach $39.15 \mathrm{~V}$ and $35.41 \mathrm{~V}$ respectively. However there exists some 
distortion in the waveform of all cases due to the odd harmonics. From this result it is obvious that all induced voltages are less than applied voltage that confirms the motor will be worked on safe region.

Magnetic flux characteristics. The magnetic flux characteristics of HEFSM, FEFSM and PMFSM with segmental rotor are compared as shown in Fig. 3. It is clear that similar magnetic flux strength of approximately $0.052 \mathrm{~Wb}$ is obtained for HEFSM and FEFSM with segmental rotor, while flux strength of PMFSM reaches to $0.043 \mathrm{~Wb}$. At this stage the flux value of HEFSM and FEFSM with segmental rotor is same due to unbalanced magnetic fluxes combinations and cancellation effects of FEC and PMs. Thus further optimization by adjusting proper position of PMs and FEC so that both fluxes of FEC and PMs can easily be combined and transferred from stator to rotor segments to generate more magnetic flux strength.

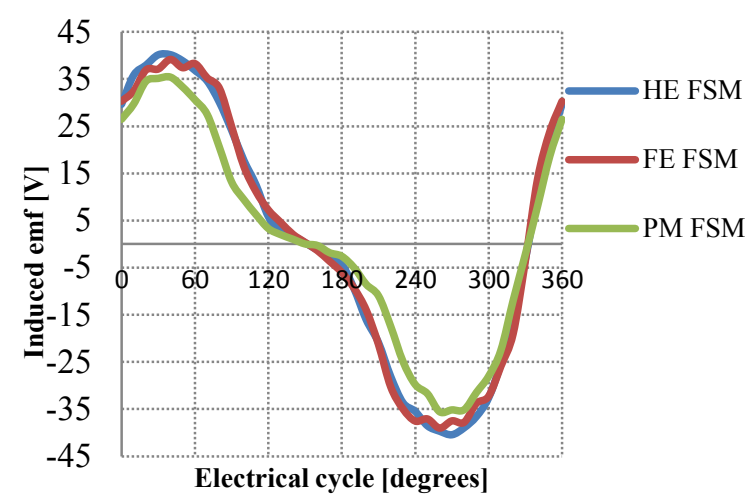

Fig. 2, Induced voltage for HE-FSM, FE-FSM and PM-FSM with segmental rotor

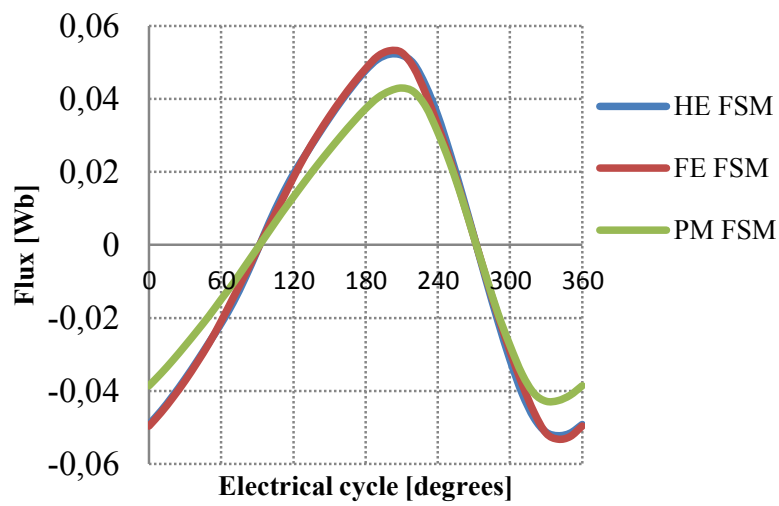

Fig. 3, Magnetic flux characteristics of HE-FSM, FE-FSM and PM-FSM with segmental rotor

Cogging torque. The comparison of cogging torque analysis of three phase HEFSM, FEFSM and PMFSM with segmental rotor is shown in Fig. 4. It is obvious that FEFSM and PMFSM have lowest and highest values of $2.88 \mathrm{Nm}$ and $8.71 \mathrm{Nm}$ respectively. On the other hand fundamentally the HEFSM with segmental rotor has moderate peak to peak value of cogging torque approximately $4.021 \mathrm{Nm}$, even though it will be further improved in optimization.

\section{Torque vs. Armature current densities Ja, at field current densities Je of $30 \mathrm{~A} / \mathrm{mm}^{2}$}

Torque vs. armature current densities Ja, at field current densities Je of $30 \mathrm{~A} / \mathrm{mm}^{2}$ of FEFSM, PMFSM and HEFSM with segmental rotor are compared as shown in Fig. 5. It is noticeable that FEFSM has torque of approximately $32.8 \mathrm{Nm}$ at Je $30 \mathrm{~A} / \mathrm{mm}^{2}$. Moreover in case of PMFSM the torque increases with the increase of armature current densities and reaches up to a maximum value of $29.5 \mathrm{Nm}$. The torque characteristic of HEFSM with segmental rotor increases linearly as the armature current density Ja is increased and reaches to the maximum value of approximately $18 \mathrm{Nm}$ at field current density of $30 \mathrm{~A} / \mathrm{mm}^{2}$. Although the torque at this stage is less as compare to FEFSM and PMFSM with segmental rotor, due to the reasons of demagnetization and flux leakage. But it is feasible to improve the torque value up to required target by several optimization methods. 


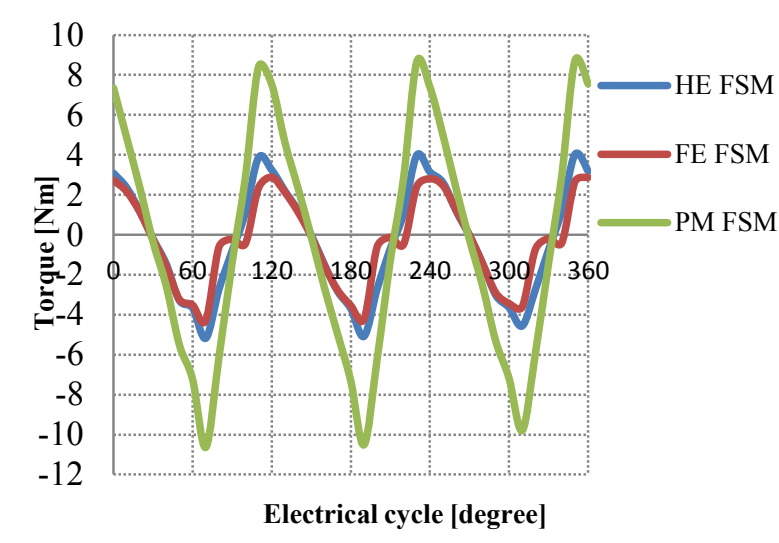

Fig. 4, Cogging torque of HE-FSM, FE-FSM and PM-FSM with segmental rotor

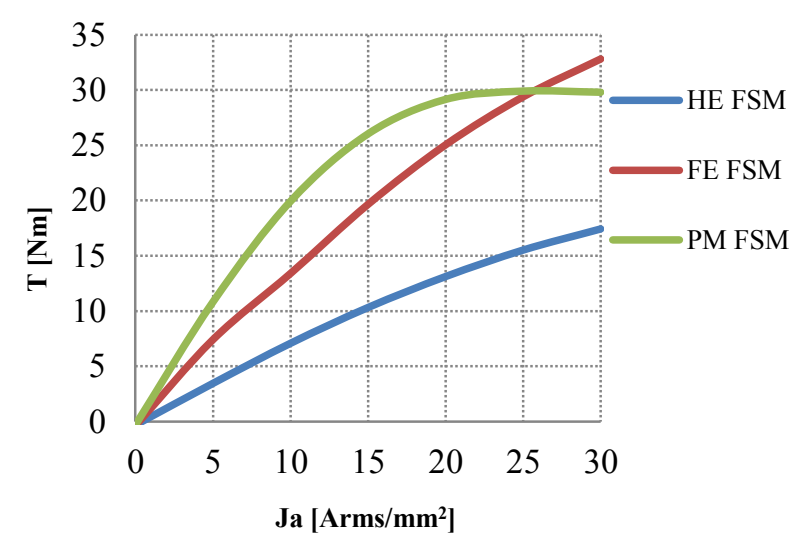

Fig. 5, Torque vs. Ja at Je of $30 \mathrm{~A} / \mathrm{mm}^{2}$

\section{Power vs. Ja at various field current densities Je}

Fig. 6 illustrates the comparison of output power vs. armature current densities Ja at maximum field current density Je of HEFSM, FEFSM and PMFSM with segmental rotor it is clear that FEFSM and PMFSM with segmental rotor have the highest values of $13.7 \mathrm{KW}$ and $12.4 \mathrm{KW}$ respectively at maximum armature current density Ja. In case of HEFSM with segmental rotor the value of power is approximately $7.3 \mathrm{KW}$ at speed of 500rpm, which is less as compared to FEFSM and PMFSM. But it will be easily increased up to a maximum value by further design optimization.

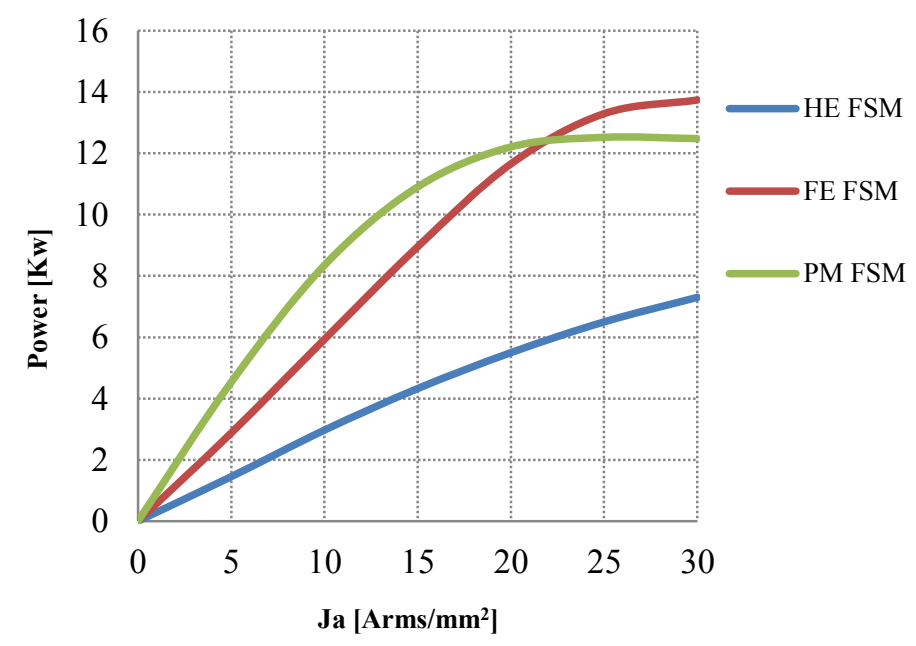

Fig. 8, Power vs. Ja, at maximum field current densities Je

\section{Conclusion}

In this paper the design study and comparative performance of HEFSM, FEFSM and PMFSM with segmental rotor have been introduced and analyzed. The magnetic flux characteristics, cogging torque, induced emf, torque and power characteristics vs. Ja at various field current densities Je, have been investigated based on 2-D FEA. Due to some drawbacks of HEFSM the performance of HEFSM with segmental rotor is not adequate as compared to FEFSM and PMFSM with segmental rotor. However it is obvious from these results that by further design improvement and optimization, the target performances of HEFSM with segmental rotor will be easily attained. 


\section{References}

[1] E. Sulaiman, M. F. M. Teridi,, Z. A. Husin, M. Z. Ahmad and T. Kosaka, Investigation on Flux Characteristics of Field Excitation Flux Switching Machine with Single FEC Polarity, International Conference on Electrical Engineering and Informatics ICEEI, (2013) pp. 561-567.

[2] E. Sulaiman, T. Kosaka, and N. Matsui, Design optimization and performance of a novel 6slot 5-pole PMFSM with hybrid excitation for hybrid electric vehicle, IEEE Trans. Ind. 132 (2012) 211-218.

[3] A.E. Laws, An electromechanical transducer with permanent magnet polarization, Technical note No.G.W.202, Royal Aircraft Establishment Farnborough, UK, 1952.

[4] S. E. Rauch and L. J. Johnson, Design principles of flux-switching alternators, AIEE Trans. 74III (1955), 1261-1268.

[5] J. H. Walker, The theory of the inductor alternator, J. IEE, 89, (1942) pp.227-241.

[6] T.J.E. Miller, Switched Reluctance Machines and Their Control, Hillsboro, OH, Mgna Physics, 1993.

[7] B. C. Mecrow, J.W. Finch, E. A. El-Kharashi, and A. G. Jack, Segmental rotor switched reluctance motor with single tooth windings, Proc. Inst. Elect. Eng Electr. Power, 150, (2003) 591 599.

[8] B. C. Mecrow, T. J. Bedford, J. W. Bennet, and T. Celik, The use of segmental rotors for 2 phase flux-switching motors, presented at the Int. Conf. Electrical Machines, Chania, Greece, 2006, Paper 608.

[9] Ackim Zulu, Barrie C. Mecrow, A wound-field three-phase flux-switching synchronous Motor with All excitation sources on the stator, IEEE transactions on industry applications, 46 (2010), 2363-2371.

[10] A. Zulu, B. C. Mecrow, and M. Armstrong, Topologies for wound field three-phase segmented-rotor flux-switching machines, in Proc. IET PEMD, (2010), 1-6. 